\title{
IDENTIFIKASI TINGKAT KELULUSAN SISWA SMA KOTA BANDA ACEH MELALUI METODE FISHER
}

\section{IDENTIFICATION OF STUDENTS GRADUATION LEVEL ON BANDA ACEH CITY SMA THROUGH THE FISHER METHOD}

\author{
Khairul Umam ${ }^{1}$, Suhartati ${ }^{2}$ \\ ${ }^{1,2}$ Department of mathematic Education, Syiah Kuala University, Darussalam, Banda Aceh. \\ E-mail: khumam77@unsyiah.ac.id
}

Diterima: 00/00/0000; Revisi: 00/00/0000; Disetujui: 00/00/0000

\begin{abstract}
ABSTRAK
Penelitian ini bertujuan untuk mengetahui pengelompokan tinggi rendahnya tingkat kelulusanSMA di Kota Banda Aceh pada tahun 2014 berdasarkan nilai rata-rata mata pelajaran.Penelitian ini menggunakan pendekatan kuantitatif.Data yang diteliti dalam penelitian ini diperoleh dari Diskominfo Kota Banda Aceh. Data tersebutdianalisis menggunakan Discriminant Fisher's melalui SPSS. Formula Discriminant Fisher's yang diperoleh adalah sebagai berikut. Untuk kelompok rendah, K1 :(-27.629)X1 + ($45.823) \mathrm{X} 2+(70.404) \mathrm{X} 3+(853.936) \mathrm{X} 4+(3.446) \mathrm{X} 5+(226.162) \mathrm{X} 6+(59.468) \mathrm{X} 7+$ $(91.345) \mathrm{X} 8+(-80.161) \mathrm{X} 9+(87.920) \mathrm{X} 10+(237.842) \mathrm{X} 11+(-70.950) \mathrm{X} 12=0$ sedangkan untuk kelompok tinggi, K2 : (-27.911)X1 + (-48.017)X2 + (78.006)X3 + $(894.813) \mathrm{X} 4+(5.304) \mathrm{X} 5+(239.969) \mathrm{X} 6+(63.206) \mathrm{X} 7+(96.425) \mathrm{X} 8+(-82.871) \mathrm{X} 9+$ $(93.122) \mathrm{X} 10+(249.551) \mathrm{X} 11+(-75.552) \mathrm{X} 12=0$
\end{abstract}

Kata Kunci: Discriminant Fisher's, Tingkat Kelulusan, Banda Aceh, Siswa, SMA.

\begin{abstract}
The study aims to determine the grouping of high and low high school graduation rates in Banda Aceh City in 2014 based on the average value of the subjects. It's used a quantitative approach. The data studied in this study were obtained from the Diskominfo of Banda Aceh City. The data were analyzed using Discriminant Fisher's by SPSS. Fisher's Discriminant Formula obtained is as follows. For the low group, K1 :($27,629) X 1+(-45,823) X 2+(70,404) X 3+(853.936) X 4+(3,446) X 5+(226,162) X 6+$ $(59,468) X 7+(91.345) X 8+(-80.161) X 9+(87.920) X 10+(237.842) X 11+(-$ $70.950) X 12=0$ while for the high group, K2:(-27.911)X1 + (-48.017)X2 + (78.006)X3 $+(894.813) X 4+(5,304) X 5+(239,969) X 6+(63,206) X 7+(96,425) X 8+(-82,871) X 9$ $+(93,122) X 10+(249.551) X 11+(-75,552) X 12=0$
\end{abstract}

Keywords: Discriminant Fisher's, graduation level, Banda Aceh, Student, High Junior School 


\section{PENDAHULUAN}

Sekolah Menengah Atas (SMA) dalam pendidikan formal di Indonesia, merupakan jenjang pendidikan menengah setelah menyelesaikan Sekolah Menengah Pertama (SMP) atau yang sederajat. SMA diselesaikan dalam kurun waktu 3 tahun, yaitu mulai kelas 10 sampai kelas 12. Pada tahun kedua tepatnya di kelas 11, peserta didikSMA wajib memilih jurusan yang tersedia, yaitu Sains, Sosial, atau Bahasa. Pada akhir tahun ketiga atau di kelas 12, peserta didik diwajibkan mengikuti Ujian Nasional (UN) yang mempengaruhi kelulusan peserta didik. Setelah lulus SMA peserta didik dapat melanjutkan pendidikan ke Perguruan Tinggi.Proses kelulusan adalah kegiatan paling akhir dari manajemen peserta didik. Kelulusan adalah pernyataan dari lembaga pendidikan (sekolah) tentang telah diselesaikannya program pendidikan yang harus diikuti oleh peserta didik. Setelah peserta didik selesai mengikuti seluruh program pendidikan disuatu lembaga pendidikan dan berhasil lulus dari ujian akhir, maka kepada peserta didik tersebut diberikan surat keterangan lulus atau sertifikat.

Kementerian pendidikan dan kebudayaan telah menerbitkan Peraturan Menteri Pendidikan dan Kebudayaan Republik Indonesia Permendikbud Nomor 4 Tahun 2018 tentang Penilaian Hasil Belajar oleh Pemerintah. Berdasarkan Permendikbud Nomor 4 Tahun 2018 dinyatakan bahwa penilaian hasil belajar oleh satuan pendidikan dilaksanakan melalui USBN dan US, sedangkan penilaian hasil belajar oleh pemerintah dilaksanakan melalui UN. Selain itu pada jenjang SMK/MAK, penilaian hasil belajar oleh pemerintah termasuk juga ujian kompetensi keahlian. Maka hasil US dan USBN menentukan kelulusan, namun kriteria minimum ditentukan oleh sekolah atau satuan pendidikan.

Ujian Nasional adalah sistem evaluasi standar pendidikan dasar dan menengah di Indonesia dan sebagai sarana untuk memetakan mutu berbagai tingkatan pendidikan satu daerah dengan daerah lain (Gultom, 2012). Ujian Nasional adalah upaya pemerintah untuk mengevaluasi tingkat pendidikan secara nasional dengan menetapkan standarisasi nasional pendidikan (Tilaar, 2006). Hasil dari Ujian Nasional yang diselenggarakan oleh Negara adalah upaya pemetaan masalah pendidikan dalam rangka menyusun kebijakan pendidikan nasional (Tilaar, 2006).

Alasan atau tujuan pentingnya diadakannya Ujian Nasional adalah sebagai berikut: pertama, untuk mendorong guru meningkatkan kualitas mengajar; kedua, untuk meningkatkan upaya-upaya bimbingan terhadap siswa yang berkesulitan belajar; ketiga, untuk mendorong guru menerapkan berbagai metode untuk memperbaiki pembelajaran; keempat, supaya siswa lebih rajin dan giat belajar; dan 
kelima, supaya orang tua lebih memperhatikan belajar anaknya (Notodiputro, 2012).

Banyak daerah maupun satuan pendidikan yang mendapati tingkat kelulusan nyaris sempurna bahkan ada yang 100 persen. Contohnya di DKI Jakarta, tingkat kelulusannya mencapai 99,99 persen. Untuk kelompok SMA, dari jumlah peserta 56.474 peserta ujian ada 9peserta didik tidak lulus. Sedangkan di kelompok SMK, dari 68.472 peserta ujian ada $21 \%$ peserta didik tidak lulus. Sedangkan Provinsi Acehada 1.121 peserta didik SMA sederajat dinyatakan tidak lulus. Namun mereka tidak lulus bukan karena nilai USBN yang tidak mencapai ketentuan nilai yang telah ditetapkan, melainkan karena tidak tuntas atau putus sekolah dan ada juga yang tidak ikut USBN. Secara nasional, angka ketidaklulusan dalam pelaksanaan ujian nasional tingkat SMA di Provinsi Aceh tercatat 3,11\% atau sebanyak 1.752 peserta didik. Angka ini merupakan angka tertinggi di Indonesia, yang disusul Provinsi Papua di peringkat dua, dan Sulawesi Tengah di peringkat tiga. Faktor yang menjadi penyebab ketidaklulusan peserta didik, di antaranya nilai rata-rata yang tidak mencukupi atau bahkan nilai harian dan rapor peserta didik yang rendah sehingga memengaruhi nilai UN peserta didik.

Analisis Diskriminan adalah salah satu teknik analisis yang terdapat pada Dependence Method, dengan ciri-ciriyaitu adanya variabel dependen dan independen. Dengan demikian, terdapat variabel yang hasilnya tergantung pada data variabel independen. Model Analisis Diskriminan ditandai dengan ciri khusus yaitu data variabel dependen yang harus berupa data kategori, sedangkan data independen justru berupa data non kategori.

Metode linear fisher's sebenarnya berasal dari statistik klasifikasi linear untuk dua populasi normal. Penyusunan fungsi descriminan fisher's dilakukan dengan bentuk kombinasi linear dari peubah-peubah yang diamati yang akan memberikan nilai keragaman sekecil mungkin bagi objek-objek dalam kelompok yang sama dan sebesar mungkin bagi objek-objek antar kelompok. Selanjutnya peubah-peubah yang signifikan dipilih untuk dimasukkan kedalam penyusunan model deskriminan dengan menguji uji indepedensi (Umam, 2018).Analisis ini didasarkan atas fungsi diskriminan yang mempunyai bentuk umum:

$$
Y_{1}=\beta_{0}+\beta_{1} X_{1}+\beta_{2} X_{2}+\ldots+\beta_{p} X_{p}+\delta_{1}
$$

\section{Analisis disciminant Fisher's merupakan} salah satu metode dalam mendapatkan fungsi diskriminan (Johnson, 1988). Metode linear fisher's sebenarnya berasal dari statistik klasifikasi linear untuk dua populasi normal. Pada metode ini pengamatan multivariat $\mathrm{X}$ ditransformasikan kepengamatan univariat $\mathrm{Y}$ dimana $\mathrm{Y}$ berasal dari populasi pertama dan kedua untuk dipisahkan sebanyak mungkin 
untuk pengamatan lainnya. Fisher's menyarankan untuk mengambil kombinasi linear dari $\mathrm{X}$ untuk menghasilkan $\mathrm{Y}$ yang merupakan suatu fungsi yang cukup sederhana untuk pemasangan dari X (Umam, 2018).

Adapun rumusan masalah yang mendasari penelitian ini adalah bagaimana model yang dapat digunakan untuk mengelompokkan tingkat kelulusan SMA yang ada di Kota Banda Aceh berdasarkan tinggi rendahnya rata-rata nilai kelulusan.

Penelitian ini dilakukan bertujuan untuk mengetahui pengelompokan tingkat kelulusan SMA yang ada di Kota Banda Aceh dengan kriteria tinggi rendahnya tingkat kelulusan berdasarkan nilai rata-ratapelajaran.

\section{METODE PENELITIAN}

Penelitian ini berkaitan dengan penelitian kualitatif dengan jenis studi literatur atau library research. Studi literatur adalah salah satu jenis kegiatan untuk mengumpulkan data yang telah diperoleh oleh peneliti sebelumnya.

Penelitian ini dilakukan dengan menganalisis data yang diperoleh dari Diskominfo Kota Banda Aceh. Data yang diperoleh tersebut berupa data kelulusan SMA di Kota Banda Aceh tahun 2014.

Subjek penelitian ini adalah 29 SMA di Kota Banda Aceh. Teknik pengumpulan data penelitian ini adalah dengan mengunduh data kelulusan tersebut yang tersedia di website Diskominfo Kota Banda Aceh. Data tersebut diolah dengan menggunakan software SPSS khususnya dalam bagian discriminant fishers untuk dikelompokkan berdasarkan tingkat kelulusan di setiap SMA.

\section{HASIL PENELITIAN DAN PEMBAHASAN}

Data yang telah didapat oleh peneliti yang bersumber dari Diskominfo Kota Banda Aceh merupakan data mentah. Berikut adalah data mentah yang telah ditabulasikan (lihat Tabel 1).

\section{Tabel 1. Data Tingkat Kelulusan SMA Kota Banda Aceh tahun 2014}

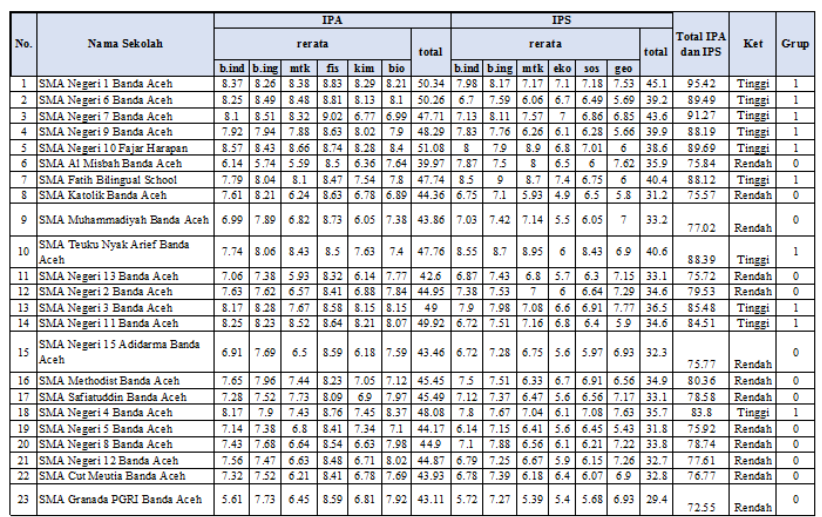

Pengelompokan setiap sekolah yang diteliti kedalam kelompok tinggi (1) dan rendah (0) dilihat dari berbagai variabel mata pelajaran yang memiliki koefisien fungsi. Koefisien fungsi ini merupakan suatu matriks baris yang menghasilkan konstanta untuk setiap kelompok tinggi dan rendah. Konstanta tersebut diperoleh dengan mensubtitusikan nilai dari setiap variabel yang diminta ke dalam suatu model 
IDENTIFIKASI TINGKAT KELULUSAN SISWA SMA KOTA BANDA ACEH MELALUI METODE FISHER

Khairul Umam, Suhartati

yang berbentuk kombinasi linear yang diasumsikan bebas linier. Koefisien yang dimaksud dapat dilihat pada gambar berikut:

\begin{tabular}{|c|c|c|}
\hline \multicolumn{3}{|c|}{ Classification Function Coefficients } \\
\hline & \multicolumn{2}{|c|}{$\mathrm{KET}$} \\
\hline & rendah & tinggi \\
\hline IPAInd & -27.629 & -27.911 \\
\hline IPAEng & -45.823 & -48.017 \\
\hline IPAMat & 70.404 & 78.006 \\
\hline FIS & 853.936 & 894.813 \\
\hline $\mathrm{KIM}$ & 3.446 & 5.304 \\
\hline $\mathrm{BIO}$ & 226.162 & 239.969 \\
\hline IPSInd & 59.468 & 63.206 \\
\hline IPSEng & 91.345 & 96.425 \\
\hline IPSMat & -80.161 & -82.871 \\
\hline EKO & 87.920 & 93.122 \\
\hline sos & 237.842 & 249.551 \\
\hline GEO & -70.950 & -75.552 \\
\hline (Constant) & -5478.388 & -6112.175 \\
\hline
\end{tabular}

Gambar 2. Koefisien fungsi

Berdasarkan gambar diatas, diperoleh model untuk pengelompokan sekolah kelompok tinggi dan rendah yaitu sebagai berikut.

Untuk kelompok rendah:

$\mathrm{K} 1: \quad(-27.629) \mathrm{X} 1+(-45.823) \mathrm{X} 2+(70.404) \mathrm{X} 3$ $+(853.936) \mathrm{X} 4+(3.446) \mathrm{X} 5+$ $(226.162) \mathrm{X} 6+(59.468) \mathrm{X} 7+(91.345) \mathrm{X} 8$ $+(-80.161) \mathrm{X} 9+(87.920) \times 10+$ $(237.842) \mathrm{X} 11+(-70.950) \mathrm{X} 12=0$

Untuk kelompok tinggi:

$\mathrm{K} 2: \quad(-27.911) \mathrm{X} 1+(-48.017) \mathrm{X} 2+(78.006) \mathrm{X} 3$ $+\quad(894.813) \mathrm{X} 4+(5.304) \mathrm{X} 5+$ $(239.969) \mathrm{X} 6+(63.206) \mathrm{X} 7+(96.425) \mathrm{X} 8$
Jurnal Geuthèë: Penelitian Multidisiplin Vol. 04, No. 02, (Agustus, 2021), pp. 68-74.

$+(-82.871) \times 9+(93.122) \times 10+$ $(249.551) \mathrm{X} 11+(-75.552) \mathrm{X} 12=0$

Model yang didapat akan diuji untuk memprediksi apakah suatu sekolah di Kota Banda Aceh pada tahun berikutnya memperoleh tingkat kelulusan yang tinggi atau rendah. Berikut nilai mata pelajaran dari suatu sekolah tersebut:

Kasus 1:

X1) IPA Bahasa Indonesia : 6.79

(X2) IPA Bahasa Inggris : 6.79

(X3) IPA Matematika : 6.79

(X4) Fisika : 6.79

(X5) Kimia : 6.79

(X6) Biologi : 6.79

(X7) IPS Bahasa Indonesia : 6.79

(X8) IPS Bahasa Inggris : 6.79

(X9) IPS Matematika : 6.79

(X10) Ekonomi : 6.79

(X11) Sosiologi : 6.79

(X12) Geologi : 6.79
Hasil Uji:

$\mathbf{K} 1=(-27.629) \mathrm{X} 1+(-45.823) \mathrm{X} 2+(70.404) \mathrm{X} 3+$ $(853.936) \mathrm{X} 4+(3.446) \mathrm{X} 5+(226.162) \mathrm{X} 6$ $+(59.468) \times 7+(91.345) \times 8+(-$ 80.161)X9 + $(87.920) \times 10+$ $(237.842) \mathrm{X} 11+(-70.950) \mathrm{X} 12$

$$
\begin{aligned}
= & (-27.629)(6.79)+(-45.823)(6.79)+ \\
& (70.404)(6.79)+(853.936)(6.79)+ \\
& (3.446)(6.79)+(226.162)(6.79)+ \\
& (59.468)(6.79)+(91.345)(6.79)+(-
\end{aligned}
$$




$$
\begin{aligned}
& 80.161)(6.79)+(87.920)(6.79)+ \\
& (237.842)(6.79)+(-70.950)(6.79)
\end{aligned}
$$$$
=9546.468
$$

$\mathbf{K} 2=(-27.911) \mathrm{X} 1+(-48.017) \mathrm{X} 2+(78.006) \mathrm{X} 3$

$$
\begin{gathered}
+(894.813) \mathrm{X} 4+(5.304) \mathrm{X} 5+ \\
(239.969) \mathrm{X} 6+(63.206) \mathrm{X} 7+ \\
(96.425) \mathrm{X} 8+(-82.871) \mathrm{X} 9+ \\
(93.122) \times 10+(249.551) \mathrm{X} 11+(- \\
75.552) \mathrm{X} 12 \\
=(-27.911)(6.79)+(-48.017)(6.79)+ \\
(78.006)(6.79)+(894.813)(6.79)+ \\
(5.304)(6.79)+(239.969)(6.79)+ \\
(63.206)(6.79)+(96.425)(6.79)+(- \\
82.871)(6.79)+(93.122)(6.79)+ \\
(249.551)(6.79)+(-75.552)(6.79) \\
\mathbf{1 0 0 9 0 . 2 5}
\end{gathered}
$$

\section{$=10090.25$}

Berdasarkan pengujian formula di atas, maka untuk setiap variabel didapat hasilnya seperti yang terlihat pada gambar berikut:

\begin{tabular}{|c|r|r|}
\hline Var & Rendah & \multicolumn{1}{c|}{ Tinggi } \\
\hline $\mathbf{1}$ & -187.601 & -189.51 \\
\hline $\mathbf{2}$ & -311.138 & -326.03 \\
\hline $\mathbf{3}$ & 478.043 & 529.66 \\
\hline $\mathbf{4}$ & 5798.225 & 6075.78 \\
\hline $\mathbf{5}$ & 23.398 & 36.014 \\
\hline $\mathbf{6}$ & 1535.64 & 1629.389 \\
\hline $\mathbf{7}$ & 403.788 & 429.168 \\
\hline $\mathbf{8}$ & 620.233 & 654.72 \\
\hline $\mathbf{9}$ & -544.293 & -562.69 \\
\hline $\mathbf{1 0}$ & 596.977 & 632.298 \\
\hline $\mathbf{1 1}$ & 1614.947 & 1694.45 \\
\hline $\mathbf{1 2}$ & -481.751 & -512.998 \\
\hline Jumlah & 9546.468 & 10090.25 \\
\hline
\end{tabular}

Gambar 3. Hasil pengujian untuk setiap variabel.

Dari data tersebut, terlihat bahwa nilai mata pelajaran sekolah tersebut cenderung tinggi pada model tingkat kelulusan tinggi, maka sekolah tersebut diprediksi memiliki tingkat kelulusan yang tinggi.

\section{SIMPULAN}

Berdasarkan hasil dan pembahasan analisis diskriminan diatas, dapat disimpulkan bahwa terdapat 12 SMA di Kota Banda Aceh yang memiliki tingkat kelulusan yang tinggi dan 17 SMA tergolong ke dalam kelompok rendah. Berikut adalah Formula Discriminant Fisher's yang diperoleh:

$$
\begin{aligned}
\mathrm{K} 1 & :(-27.629) \mathrm{X} 1+(-45.823) \mathrm{X} 2+(70.404) \mathrm{X} 3 \\
& +(853.936) \mathrm{X} 4+(3.446) \mathrm{X} 5+(226.162) \mathrm{X} 6 \\
& +(59.468) \mathrm{X}+(91.345) \mathrm{X} 8+(-80.161) \mathrm{X} 9 \\
& +(87.920) \mathrm{X} 10+(237.842) \mathrm{X} 11+(- \\
& 70.950) \mathrm{X} 12=0 \\
\mathrm{~K} 2 & :(-27.911) \mathrm{X} 1+(-48.017) \mathrm{X} 2+(78.006) \mathrm{X} 3 \\
& +(894.813) \mathrm{X} 4+(5.304) \mathrm{X} 5+(239.969) \mathrm{X} 6 \\
& +(63.206) \mathrm{X} 7+(96.425) \mathrm{X} 8+(-82.871) \mathrm{X} 9 \\
& +(93.122) \mathrm{X} 10+(249.551) \mathrm{X} 11+(- \\
& 75.552) \mathrm{X} 12=0
\end{aligned}
$$




\section{DAFTAR PUSTAKA}

Diskominfo Kota Banda Aceh. Daftar Kelulusan SMA Kota Banda Aceh.Diakses melalui http://data.bandaacehkota.go.id/index.php/dataset/daftar-kelulusan-sma-kota-bandaaceh/resource/aea0f1c7-482e-4670-b0eb-4da0419e8e98

Gultom, S. (2012). Ujian Nasional Sebagai Wahana Evaluasi Pengembangan Pendidikan Karakter Bangsa. Yogyakarta: Program Pascasarjana UNY.

Heristina, A. (2014). Standar Kelulusan.

Johnson, R, A, Wichern, D. W..(1988). Applied Multivariate Statistical Analysis. Prentice Hall, Inc: New jersey

Kementerian Pendidikan dan Kebudayaan. (2018). Permendikbud Nomor 4 Tahun 2018 tentang Penilaian Hasil Belajar. Diakses melalui: https://www.kemdikbud.go.id/.../2018/.../permendikbud-nomor-4-tahun-2018-tentangpenilaian-hasil-belajar

Notodiputro, K.A. (2012). Ujian Nasional:Sarana Untuk Membangun Karakter Bangsa. Jakarta: Kementerian Pendidikan dan Kebudayaan

Tilaar, H. A. R. (2006). Standarisasi Pendidikan Nasional: Suatu Tinjuan Kritis. Jakarta: Rineka Cipta.

Umam,K. (2018). Diskriminan Fisher's. Diakses melalui:

www.informatika.unsyiah.ac.id/umam/diskriminan.pdf. 